\title{
The Construction of Human Resource Management Cloud Service Platform
}

\author{
Liangtie Dai, Yang He, Guangdong Xing \\ Management School, Jinan University, Guangzhou, China \\ Email: heyang168@gmail.com
}

Received 5 December 2014; revised 20 December 2014; accepted 6 January 2015

Copyright (C) 2015 by authors and Scientific Research Publishing Inc.

This work is licensed under the Creative Commons Attribution International License (CC BY). http://creativecommons.org/licenses/by/4.0/

c) (i) Open Access

\begin{abstract}
Human resource management service faced the challenges of promoting efficiency, costs saving, quick responding and so on. In order to face these challenges, this paper puts forward a " $6+1$ " structure of human resource management service combined with some characteristics of cloud computing, elaborates the service mode of the cloud service platform based on this structure, the characteristics and challenges of the platform, and hopes to provide a new service perspective to human resource management.
\end{abstract}

\section{Keywords}

Human Resource Management, Cloud Service Platform, Structure, Service Mode

\section{Introduction}

According to the definition of the National Institute of Standards and Technology (NIST), cloud computing is a configurable computing resources shared pool (e.g. network, sever, application and service). Cloud computing services allow individuals and businesses to use software and hardware that are managed by third parties at remote locations [1]. It can provide convenient and pay-as-you-go model network access mode. In this way, users can quickly allocate the resources with lower management invest.

With the rapid popularization of information technology, human resource management service faced the challenges of promoting efficiency, costs saving, quick responding and so on. Cloud computing has the characteristics of cheapness, efficiency and high expansibility; these characteristics can meet the challenges suitably. Therefore, how to build a comprehensive and efficient human resource management cloud service platform becomes a key point to meet these challenges. In existing researches, developers often develop the system of a certain module of human resource management, such as recruitment management system [2], information system [3] [4], or analysis on the concept of service mode [5], but there are few researches about the structure and 
service mode of comprehensive cloud service platform. This paper puts forward a " $6+1$ " structure of human resource management combined with some characteristics of cloud computing, and elaborates the service mode of this platform.

In Section 2, the service modes of cloud service (SaaS and PaaS) will be described; in Section 3, the basic form of " $6+1$ " structure will be introduced; in Section 4, the writer will draw up the flow chart of the cloud service platform and introduce the service contents of the platform; in Sections 5 and 6, the characteristics and challenges of the platform will be presented.

\section{Service Modes of Cloud Service}

There are mainly three kinds of service modes of cloud service, they are IaaS (Infrastructure as a Service), SaaS (Software as a Service) and PaaS (Platform as a Service). The IaaS mode provides just the hardware and network, it's not suitable for the clients of human resource management service, so this paper doesn't do detailed introduction.

SaaS is a main service mode of cloud computing. In SaaS mode, developers develop B/S software and install on the sever; clients across different regions run the software on their own devices through the internet, conduct inquiring, adding, modifying, calling, sharing and decision-making operations, and save the results on the sever. In practice it has proved that human resource management in different organizations has some generality. If developers build a normalized human resource management cloud service platform, organizations don't need to develop their own human resource management system and can use the services in the "cloud" to achieve comprehensive human resource management. The " 6 " structure of " $6+1$ " structure in this paper is based on SaaS mode.

PaaS is another main service mode of cloud computing. In PaaS mode, providing platform is a kind of service, developers provide ready-made platform and development window to other service providers (e.g. human resource management expert and psychology expert). This way, the cloud service platform can provide many characteristic services to clients, and clients can get project solutions when faced the non-canonical problems. In PaaS mode, the cloud service platform can combine many theories, methods and tools of different experts organically, and can provide more comprehensive services to clients. The " +1 " structure of " $6+1$ " structure in this paper is based on PaaS mode.

\section{The "6 + 1" Structure Human Resource Management Cloud Service Platform}

\section{1. "6" Structure to Implement Normalized Human Resource Management Service}

As mentioned above, human resource management has some generality (e.g. wage management, attendance management and personnel file management). The cloud service platform can provide normalized service of the generality parts to different clients. The process of normalized service should be like this: the platform gets raw data from the clients according to their demands, processes these data through appropriate human resource management methods or models, and returns the results to clients in the end. The writer puts forward a "6" structure to support the data processing and flowing of normalized human resource management service.

The first layer is page layer, it's used to face the clients and collect the data. In the page layer, clients chose the services (e.g. salary management, performance management or recruitment management) they deeded.

The second layer is page control and common algorithm layer, it's used to control the integrity and standardization of the received data, and ensure the data could be processed.

The third layer is professional algorithm layer; it's used to process the data. This layer is the core part of the whole platform, contains many algorithms of statistical models, operational research models and management models. In this layer, many structured and semi-structured theories, methods and tools turn into clear computer problem-solving processes; clients can solve the normalized problems efficiently.

The forth layer is logic layer, it's used to control the inquiring, adding, modifying, deleting etc. operations of data in each data table of the database.

The fifth layer is data table definition layer, it's used to define the fields, field properties and field control conditions in each data table of the database.

The sixth layer is database layer, it's used to establish connections between foreground data and background data, and implement calling and saving of the data. 


\section{2. "+1" Structure to Implement Characteristic Human Resource Management Service}

In practice work, human resource management business is not always normalized, such as organizational structure adjustment, salary system design and psychological counseling to the employees. These problems usually require relevant experts to solve based on their experience. Meanwhile, many experts have characteristic methods and theories, they need working platforms to provide services. The cloud service platform can help them build their own sub working platforms, and offer technical support. This is the "+1" structure to implement characteristic human resource management service.

\section{Service Mode of Human Resource Management Cloud Service Platform}

\subsection{Client Demands Response Process}

\subsubsection{Normalized Human Resource Management Service}

As shown in Figure 1, clients use network devices visit the cloud service platform through the internet. The page layer presents services of human resource management; clients choose the service they needed. Then clients upload corresponding data to the platform; these data will be saved in the database through logic layer, data table definition layer and database layer. After receive the data, the page control and common algorithm layer will call the data from the database and judge the integrity and standardization of data according to the processing conditions of algorithms; if it's not suitable for further processing, the platform will return the wrong data to clients; clients modify the data and upload again. After getting suitable data, the professional algorithm layer will call appropriate algorithms to process the data; the results will be saved in the database still through logic layer, data table definition layer and database layer. At the same time, the results will return to the devices and finally present to clients. The results saved in the database can also be called by other functions of the platform.

\subsubsection{Characteristic Human Resource Management Service}

As shown in Figure 1, technical staffs of the cloud service platform offer hardware and technic support to other human resource management experts and psychology experts, help them build sub working platform based on the cloud platform. There is no specialized form of the sub working platform; it may be video, audio and text connection system, or method base and tool base like the normalized human resource management service, or even the combination of both. Clients visit appropriate expert sub working platform to obtain services when faced the non-canonical problems. The cloud service platform controls the charging, maintaining and updating of each sub platform.

\subsection{Service Contents of the Platform}

\subsubsection{Human Resource Management Services}

The cloud service platform provides comprehensive human resource management services, covers all contents of human resource management business.

- Organization and job management system

1) Organization management system contains: organization structure design, department responsibility management, position establishment management, staff establishment management, statistics of the basic information of the human resource management;

2) Job management system contains: job analysis questionnaire, position analysis questionnaire, job evaluation, work log, detailed record of work days, competency model.

- Human resource planning management system

Human resource strategy plan, staff recruiting plan, staff using plan, staff replacement and promotion plan, staff education and training plan, employee satisfaction survey, staff motivation plan, retirement and layoff plan.

- Recruitment management system

1) Recruitment preparation system contains: recruitment requirements management, recruitment plan system;

2) Recruitment implementation system

a) Psychological test system contains: Cartel-16PF, Holland professional interest examination, Eysenck personality questionnaire, temperament test, intelligence test, general ability test;

b) Leadership effectiveness evaluation; 


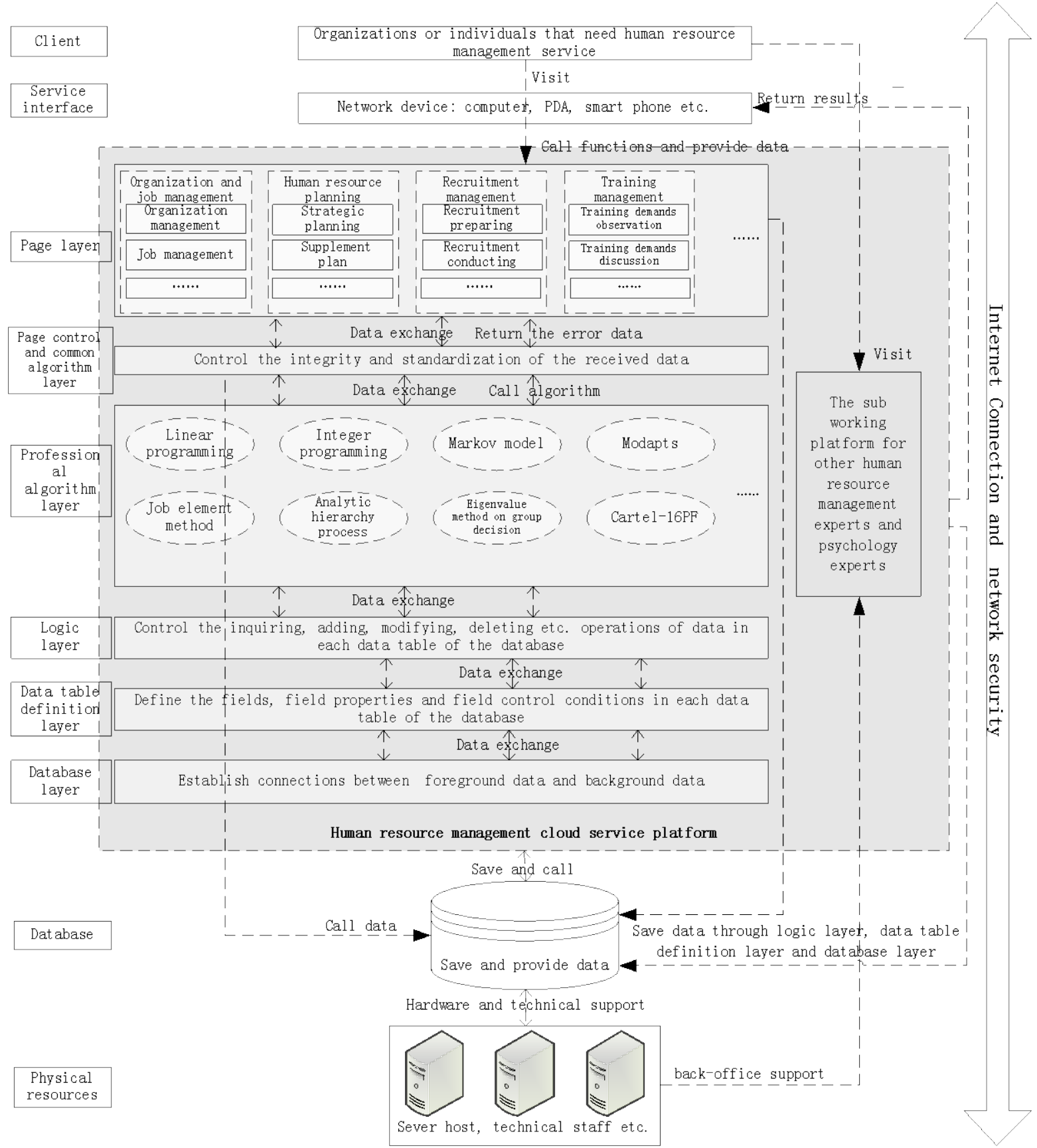

Figure 1. Human resource management cloud service platform.

c) Assessment center contains leaderless group discussion, document processing, case analysis, subject debating or discussion;

d) Interview management system contains ordinary interview, structured interview, integrated management of the interview;

e) Recruitment comprehensive evaluation contains applicant qualification assessment, applicant comprehensive assessment.

\section{- Training management system}

Training needs questionnaire, training needs summary, training plan management, training preparation management, training tracks, training evaluation. 
- Performance management system

Enterprise strategic indicators management, department performance indicators management, staff performance indicators management, department performance coaching, staff performance coaching, department rewards and punishment record, staff rewards and punishment record, department comprehensive assessment, staff 360-degree assessment, staff simple ranking method assessment, staff alternation ranking method assessment, staff matching ranking method assessment, staff forced distribution method assessment, staff balance scorecard assessment, staff KPI assessment, department performance feedback, staff performance feedback.

- Salary management system

Bonus and subsidy management, deduction management, tax rates table management, broadband salary data management, wage management.

- Career management

Staff basic information analysis, work-social environment analysis, staff key information analysis, staff career questionnaire, staff career planning management, employee assistance program management, reserved talents management, cadre promotion planning.

- Labor relation management system

Labor contract management, renewal of labor contract management, modification of labor contract management, termination of labor contract management, labor agreement management, demission management, personnel disputes management.

- Human resources management diagnosis system

Human resource management index survey and analysis, job satisfaction survey and analysis, enterprise cohesion survey and analysis, enterprise culture survey and analysis, personal development survey and analysis, performance management effect survey and analysis, training effect survey and analysis, salary and welfare effect survey and analysis, staff needs survey and analysis, organization situation survey and analysis, labor relation survey and analysis, team spirit survey and analysis, recruitment effect survey and analysis.

- Daily management system

1) Personnel file management system;

2) Attendance management system contains staff vacation standard, full-attendance standard, vacation management and attendance management.

\subsubsection{Professional Algorithms}

Many professional algorithms support the realization of the services above, and offer scientific basis for human resource management. They are: linear programming, integer programming, Markov model, MODAPTS, predetermined time standard, job element method, analytic hierarchy process, eigenvalue method on group decision, Cartel-16PF, queuing theory and other statistical and psychological methods.

Linear programming, integer programming, Markov model and other statistical methods are usually applied to human resource planning management; these algorithms can improve the accuracy of human resource plan. MODAPTS, predetermined time standard, job element method, queuing theory and other methods are quantitative methods in the field of labor norm, the application of these methods can rid labor norm of subjective judgment. Analytic hierarchy process and eigenvalue method on group decision are new methods in the field of salary management and performance management, these methods may provide a new perspective to traditional human resource management. Cartel-16PF and other psychological tests can provide scientific basis for recruitment. The professional algorithms in the service platform are too many to cover here; this paragraph is just a brief introduction.

As the abundance of theories and methods, the cloud service platform should supplement new services and algorithms and update existing contents in time to keep the comprehensiveness and professionalism.

\section{The Characteristics of the Human Resource Management Cloud Service Platform}

- No regional restriction. Clients visit the platform through internet, so they can get services wherever they are. The cloud service platform is especially suitable for the clients whose businesses are multi-geographic or large-scale.

- Efficient. The services are provided online, it's much faster than offline services. Meanwhile, the results can 
be recalled by other appropriate functions, this way improves the data utilization.

- Comprehensive. The cloud service platform provides normalized human resource management service and characteristic human resource management service, can meet the demands of various types of clients.

- Pay-as-you-go. Clients choose the service they needed and pay for it. In this payment mode, clients don't need to buy a whole set of software and waste money on the services they don't need.

- High expansibility. The cloud platform will provide interfaces to the new trend of human resource management service. The platform will add new functions and methods as they arise.

\section{The Challenges of the Human Resource Management Cloud Service Platform}

- Cloud security issues. Cloud service relies heavily on the network, it's hard to avoid the negative effects of data leakage, service loss (e.g. service interruption and service termination), service impairment and control loss [6]. Ensuring the cloud security requires not only technical improvement but also further perfecting the law.

- Network-transmission problems. The network speed is slow and unstable in some places at present; this may greatly reduce the user experience of cloud service platform. The popularization of cloud computing depends on the development of network technic.

- The lack of developers of the platform. One of the prominent problems existed in human resources management informationization is that the IT abilities of human resources management experts are poor [7] [8]. However, turning structured and semi-structured management theories, methods and tools into clear computer problem-solving processes is the most important work of the developers, this work requires both rich knowledge of management and good IT abilities. The contradiction between these two phenomenon leads to the lack of developers of the platform

\section{Conclusion and Research Prospect}

This paper conducts preliminary discussion focusing on the structure, service mode, characteristics and challenges of the human resource management cloud service platform. The cloud service platform is very practical and needs to be perfected in practice. The updating of structure and service mode is the key point in the future; developers should pay close attention to the new services and new methods in the field of human resource management, and study the feedback of clients seriously.

\section{References}

[1] Sandeep, K. and Rachana, C.R. (2014) Cloud Computing - Challenges Ahead for Human Resource Managers. International Journal of Scientific Research, 3, 35-38. http://dx.doi.org/10.15373/22778179/APR2014/224

[2] Wei, B. (2012) Recruitment Management System Based on Cloud Computing. Information technology, 31, $108-109$.

[3] Jahan, S. (2014) Human Resources Information System (HRIS): A Theoretical Perspective. Journal of Human Resource and Sustainability Studies, 2, 33-39. http://dx.doi.org/10.4236/jhrss.2014.22004

[4] Ma, H.Y. and Wang, J.C. (2014) An Information Configurable System for Human Resource Management Based on Cloud Computing. Logistics Engineering and Management, 36, 121-122.

[5] Li, J.R. and Wang, X.H. (2014) Research on Business Model Based on Cloud Computing of Human Resource Service Enterprise. Human Resources Development of China, 31, 19-23.

[6] Géczy, P., Izumi, N. and Hasida, K. (2012) Cloudsourcing: Managing Cloud Adoption. Global Journal of Business Research, 6, 57-70.

[7] Xiong, J. (2006) The Application Research of Human Resource Management Informationization in Enterprises. China Management Informationization (General), 9, 12-13.

[8] Du, P.C., Li, M. and Tong, Y. (2014) Adaptive Transforms of Human Resource Management in the Age of Cloud Computing. Human Resources Development of China, 30, 14-18. 
Scientific Research Publishing (SCIRP) is one of the largest Open Access journal publishers. It is currently publishing more than 200 open access, online, peer-reviewed journals covering a wide range of academic disciplines. SCIRP serves the worldwide academic communities and contributes to the progress and application of science with its publication.

Other selected journals from SCIRP are listed as below. Submit your manuscript to us via either submit@scirp.org or Online Submission Portal.
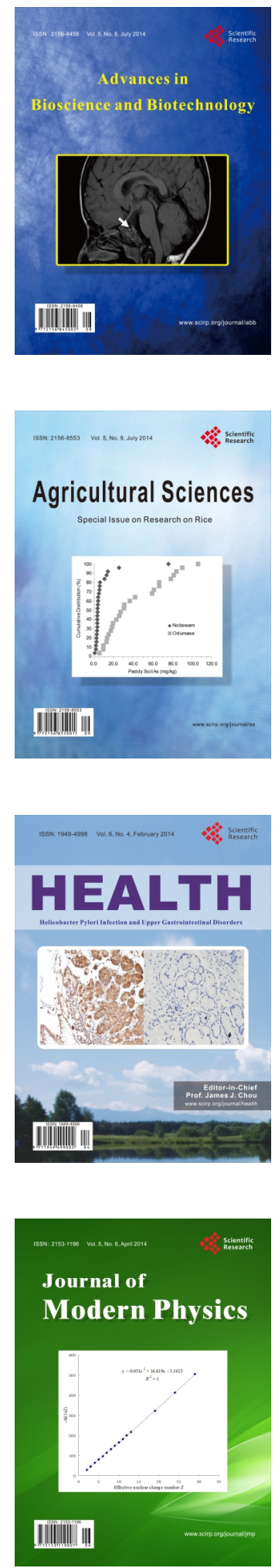
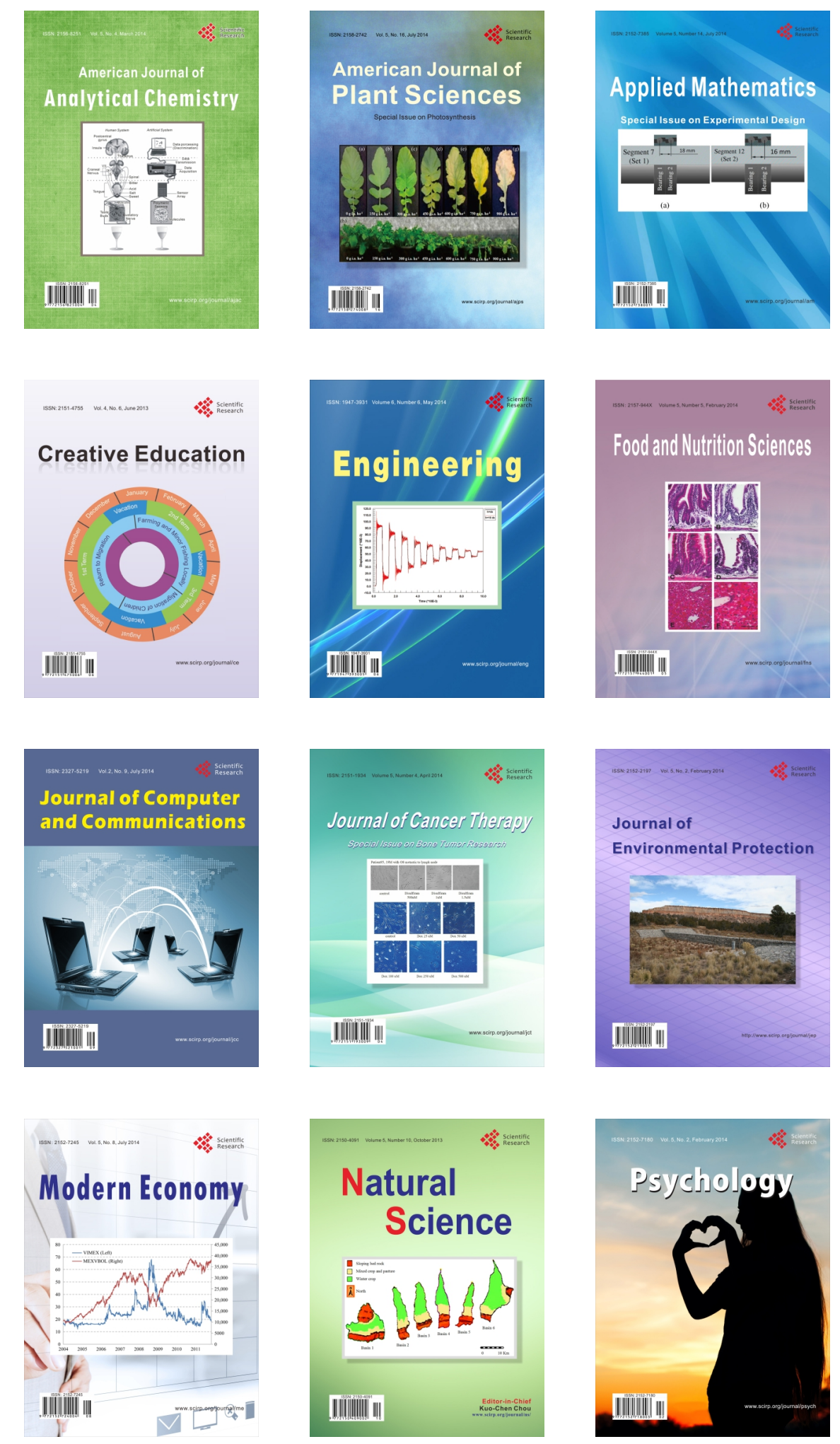